\title{
Student Engagement in the Co-designing and Co-teaching a Cornerstone EECS Design and Implementation Course at National Taiwan University
}

\author{
Jennifer Wen-Shya Lee ${ }^{1}$, Kun-You Lin ${ }^{1}$, Ho-Lin Chen ${ }^{1}$, Jiun-Peng Chen ${ }^{1}$, \\ Shih-Yuan Chen ${ }^{1}$, Chien-Mo Li ${ }^{1}$, Rui-Fu Xü ${ }^{1}$, Tzi-Dar Chiueh ${ }^{1}$, Hsiao-Wen Chung ${ }^{1}$, \\ Niccolo Chen ${ }^{2}$, Shi-Chung Chang ${ }^{1}$ \\ ${ }^{1}$ Department of Electrical Engineering, National Taiwan University, Taiwan ROC \\ ${ }^{2}$ Consultant, Actions Semiconductor Co.
}

\begin{abstract}
International higher education policies and literature have called for students and faculty to collaborate effectively in the co-designing and co-teaching of curricula. In the fall of 2017, the Department of Electrical Engineering of National Taiwan University launched the "Creative Cornerstone Course Design for ICT ${ }^{1}$ and Engineering Education" course, which is a co-design course, to engage higher division and graduate students in co-creating and coteaching the curriculum of a "Cornerstone EECS Design and Implementation" freshman course, which was a cornerstone course to be conducted in the spring of 2018. This paper presents the educational practice and learning outcomes of the co-design course. The implementation of the co-design course involved the following activities: (a) project- and team-based learning approaches, $(b)$ active student partnership with teachers for designing the cornerstone course curriculum, and (c) preparatory cultivation of the students as teaching assistants for co-teaching. Learning outcome analysis indicated that freshman students significantly benefited in terms of their self-exploration of ICT-related subjects, basic professional knowledge, operational techniques, and confidence in self-learning when the cornerstone course was developed through co-designing.
\end{abstract}

Keywords: cornerstone course; curriculum co-design; electrical engineering education; project-based learning; student partnership.

\footnotetext{
${ }^{1}$ ICT: Information and Communication Technology.
} 


\section{Introduction}

Student-centered course design and student participation have long been the key themes of higher education reforms worldwide. Although educational institutions rarely make students substantive partners in designing courses and providing advice on teaching content, the idea of students becoming teaching assistants (TAs) and co-creators of their own learning has received increasing attention in recent years (Mihans et al., 2008). Many studies have indicated that close interaction between students and instructors is one of the most important factors for students' self-learning, positive development, active engagement, and high satisfaction in higher education (Kuh et al., 2005). Teachers and students can co-create courses on university campuses by using two common models (Bovill \& Felten, 2016): one model involves hiring students as consultants to advise on teaching content and methods (Curra \& Millard, 2016), whereas the other method involves forming a team of students, course instructors, and educational developers to create a curriculum design (Mihans et al., 2008; Delpish et al., 2010). Both students and teachers can benefit from partnerships. Collaboration between students and teachers enables better understanding of the perspectives held by people at different positions in the teaching and learning field. Notably, the potential changes in the power of teaching in the educational practice improve the teaching and classroom experience, which promotes equal interaction between teachers and students at university campuses (Delpish et al., 2010).

Since 2016, the Department of Electrical Engineering at National Taiwan University (NTUEE) has initiated undergraduate curriculum reform to achieve the university's goal of advancing with the times and cultivating excellence, which is in line with the international trend of innovation in engineering education (Dym, 2013; Johri, 2014). In specific, there have been a strong dirve to motivate freshman students through engineering design, implementation and team work for their later study of the basics and project-based exploration of the rich subjects in the field of EECS. In the fall of 2017, the NTUEE launched the "Creative Cornerstone Course Design for ICT and Engineering Education" course to engage students in co-creating the curriculum of the "Cornerstone EECS Design and Implementation" freshman course that was to be taught in the spring of 2018. The department also invited one senior professional from the Center for Teaching and Learning Development to assist in the evaluation of curriculum development and the corresponding learning outcomes. This paper reports the first-stage of the development and implementation of the aforementioned two innovative courses in the 2017-2018 academic year. 


\section{Background of Freshman Course Reform}

Most graduates of the NTUEE, who were from the top $0.5 \%$ of high school students, have achieved success in their careers and have made substantial contributions to industries and society. However, on a review of their university education, some alumni have lamented that most classes conducted by the NTUEE are unidirectional and teacher-centered. Many NTUEE faculty members have also advocated the need for curriculum overhaul to not only catch up with the fast pace of global development but also nurture future leaders. Teachers and students in the NTUEE are suggested to initiate changes in traditional teaching and learning patterns as well as collaborate for addressing the challenges caused by new teaching and learning trends to achieve innovation.

Since the 2016-2017 academic year, the NTUEE has initiated compulsory curriculum planning with the restructuring and transformation of teaching models. At the invitation of the department chairman and two professor leaders, 13 professors joined the innovative curriculum development team in January 2017. Referring to the effective methodologies and successful practices of cornerstone engineering courses reported in the literature (Vallim et al., 2006; Whitfield et al., 2011; Thompson, 2012) and considering the specific needs of NTUEE freshman students, the team conducted a series of brainstorming sessions to discuss the development and planning direction of new innovative courses. In June 2017, the department's curriculum committee approved the introduction of two new elective courses during the 2017-2018 academic year. The "Creative Cornerstone Course Design for ICT and Engineering Education" course (referred to as the co-design course) was open to junior college students and above. The main goal of this course is to guide students in creating teaching materials related to engineering introductory design that can be used as the teaching content and learning activity basis in the "Cornerstone EECS Design and Implementation" course (referred to as the freshman cornerstone course).

\section{Action Research Framework of Course Development and Practice}

The developmental processes of the aforementioned two innovation courses involved a continuous cycle of introspection, which included focusing on problem areas, developing action plans, seeking partners, implementing action plans, and conducting introspection evaluations and improvements.

The process of action research in the course development is displayed in Figure 1. The process involved the following steps:

1. Defining the Education Problem: A first-year electrical engineering course that can become a cornerstone course in the department was developed.

2. Planning the Iterative Development of the Courses: Two innovative courses were 
offered. In the winter of 2017, the senior co-design course was introduced for students to jointly develop the teaching content and materials of the new freshman course. The teaching materials created by the students and teachers were implemented and evaluated in the freshman cornerstone course conducted in the spring of 2018.

3. Seeking Educational Expert Cooperation: The assistance of the Center for Teaching and Learning Development of NTU was sought for evaluating the teaching effectiveness and learning outcomes of the freshman cornerstone course.

4. Taking Action for Research and Course Implementation: Collaboration was conducted with education researchers to collect quantitative and qualitative data on student learning outcomes in the freshman cornerstone course conducted in the spring of 2018.

5. Evaluation Analysis and Reflection: Quantitative and qualitative data and the feedback from teachers and students were analyzed; the teaching effectiveness of the course was evaluated and reflected on, and the overall results were reported to the department.

6. Redefining the Problem and Strengthening PBL: The senior co-design course was continuously offered in the winter of 2018 to implement the course development plan as well as to improve the co-designed lesson plans and project-based learning (PBL) activities for the freshman cornerstone course conducted in the spring of 2019.

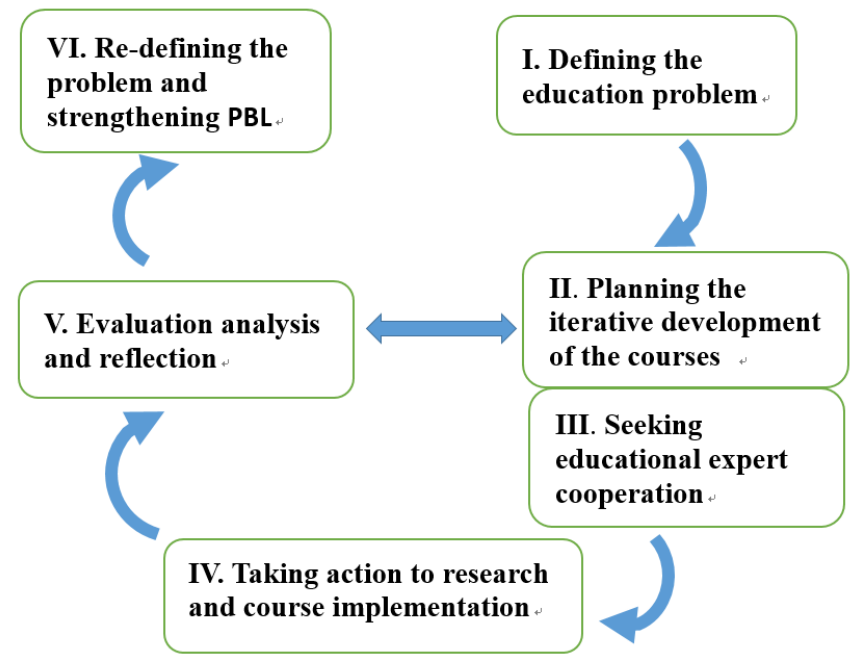

Figure 1. Process of action research in course development 


\section{Practices in the Senior Co-Design Course}

The NTUEE developed a new course titled "Creative Cornerstone Course Design for ICT Engineering Education," first offered in the winter of 2017.

\subsection{Teaching and Learning Objectives}

The teaching and learning objectives were as follows:

- Reading and analyzing the curriculum concepts and practices of Taiwanese and foreign engineering cornerstone courses.

- Co-designing a curriculum suitable for freshman students through the PBL approach.

- Enhancing students' PBL experience, executive management, and team communication skills to cultivate TAs for the freshman cornerstone course.

\subsection{Course Progress}

The course progressed as follows:

- Review of student-centered curriculum design and teaching method, analysis of literature and case studies, and performance of group briefings and discussions.

- Group-specific thematic concept design and key planning, including outlining thematic concepts, estimating resource requirements, and planning detailed design schedules.

- Group custom project design, practical verification, and presentation (5 weeks), including thematic detail design, feasibility verification, integration of design and presentation, and writing development reports.

- Design and display of an introductory workshop unit and thematic lesson plan division (5 weeks), including designing detailed software, hardware, system platform, and unit introductory lesson plans; industry teacher sharing (Songhan and Microsoft); feasibility verification and demonstration cross-group integration of design norms; and writing reports of lesson plans.

- Teachers' group guidance during the winter vocation, used to revise and supplement the group teaching plans.

\subsection{Learning Assessment}

Assignments for the first half of the semester included reading materials before class, oral and written presentation about unit topics in class, and completing hands-on tasks after class. Each teacher conducted the first evaluation and provided written comments and suggestions. The project assignment in the second half of the semester involved designing and verifying 
the topic and relevant teaching materials for the freshman cornerstone course to be conducted in the following semester. The students reported the group work progress weekly in the classroom. Moreover, through interactive discussions with the teacher group, they strengthened the design and practical verification of the curriculum plans. At the end of the semester, the group teaching material design projects were demonstrated. The teacher group provided a ranking and comments for the teaching plan design of each group according to the grading criteria of fun, completeness, and creativity. The group-written reports of the students on the teaching design, such as the experimental design ppts, lesson plans, and implementation results, were read and graded in detail by the teachers. Furthermore, the coordinating faculty member called for the students to collaborate with the teacher group for modifying and strengthening the teaching material during the winter vacation.

\subsection{PBL Products}

The 2017 co-design course comprised 16 uper division undergraduate and eight graduate students. The students were guided by eight teachers to explore and develop practical topics and teaching materials suitable for the freshman students of the NTUEE. The students formed groups and cooperated in designing various teaching units, including those related to wireless communications, control technology, machine learning, optoelectronics, electronics, and mechanical design. Through collaborations among the students and teachers, a five-unit material and a few group project teaching plans were designed on the theme of "pathfollowing and treasure-hunting robots." These materials were implemented during the first half of 2018 in the freshman cornerstone course.

\section{Analysis and Discussion}

\subsection{Implementation of Co-Design Curriculum}

The cornerstone course was first offered in the spring of 2018. The teaching team comprised six faculty and one industry teacher and nine TAs, who participated in teaching material design. A total of 57 freshman students were enrolled and divided into three classes. Unit workshops were conducted in the first 7 weeks. Each workshop comprised a 50-minute lecture and 100-minute group practice. The students then had six weeks to discuss and implement their group projects that integrate the ICT knowledge learned in unit workshops for constructing autonomous path-following cars, developing functional algorithms, coding and solving deisgn bugs. At the end of the semester, the students demonstrated their designs that could complete the required tasks and some additional self-selected tasks. 
Table 1. Summary of self-perception scores regarding unit learning

\begin{tabular}{lccccc}
\hline Domain & $\begin{array}{c}\text { Number of } \\
\text { questions }\end{array}$ & $\begin{array}{c}\text { Pre-score } \\
(\mathbf{m e a n} \pm \text { SD, })\end{array}$ & $\begin{array}{c}\text { Post-score } \\
(\mathbf{m e a n} \pm \text { SD })\end{array}$ & P-value & Effect size \\
\hline Basic knowledge & 6 & $2.92 \pm 1.97$ & $6.29 \pm 1.87$ & $\begin{array}{c}\text { All } \\
\mathrm{P}<0.001\end{array}$ & 1.52 \\
$\begin{array}{l}\text { Operational } \\
\text { techniques }\end{array}$ & 9 & $3.40 \pm 1.94$ & $6.90 \pm 1.94$ & $\begin{array}{c}\text { All } \\
\mathrm{P}<0.001\end{array}$ & 1.65 \\
$\begin{array}{l}\text { Independent } \\
\text { learning }\end{array}$ & 4 & $5.34 \pm 2.34$ & $6.76 \pm 1.86$ & $\begin{array}{c}\text { All } \\
\mathrm{P}<0.001\end{array}$ & 0.71 \\
\hline
\end{tabular}

The scores represent the self-perception scores (1-10) in the questionnaires filled before and after the unit workshops. A total of 19 questions related to the five-unit teaching material for the workshops were asked. The response rates of all the 57 students were $>75 \%$.

The overall learning perception by the freshman students indicated that the teaching materials and learning activities related to the track-based self-driving car project produced suitable learning outcomes. After the unit workshops, the self-evaluation scores of the freshman students significantly increased, including the scores for questions about basic professional knowledge, knowledge of operational techniques, and confidence in independent learning (all P $<0.001$, Table I). However, compared with basic professional knowledge and operational techniques, which exhibited a large effect size (average score increase $=3.37$ and 3.40 , respectively, and effect size $=1.52$ and 1.65 , respectively), the confidence in independent learning exhibited a considerably smaller increase in scores and moderate effect size (average score increase $=1.42$ and effect size $=0.71$ ).

\subsection{Self-Evaluation of Co-Teaching Performance}

One special feature of the freshman cornerstone course was that the teaching team invited the students with excellent performance in the senior co-design course to serve as TAs. In other words, the NTUEE provided an opportunity to junior students and above to become TAs who used the teaching materials that they contributed in designing to guide freshmen in the cornerstone course. In the weekly classes, the TAs assisted the instructors to dynamically fine-tune the content and implementation progress of the lesson plan according to the learning responses of the freshman students and the difficulties raised by them. In many situations, the TAs were more familiar with the implementation details than the faculty and thus identified students' learning problems more efficiently. This type of co-teaching is a completely new method of cooperation between faculty members and TAs at NTUEE. 
According to the results of the TA work experience questionnaire, the average self-evaluated score of teaching ability and performance was approximately 80 points. A higher score was observed for the question related to the ability of performing TA work (82.5). A marginally lower score was observed for the question related to guiding students to solve problems independently instead of directly answering questions (76.7). The main skills acquired by the TAs included skills related to teaching, curriculum and project design, deepening the course expertise, and team organization and cooperation. Some difficulties encountered were (1) unfamiliarity of TAs with the content not designed by themselves and inability to efficiently answer questions related to this content and (2) insufficient instructional guidance and curriculum design for implementing teaching smoothly.

\subsection{Observation Analysis}

According to the findings for the interaction mode between the teaching team and the students as well as for the overall course operation, some student and TA learning outcomes may be marginally unfavorable due to two factors. First, the teaching team focused on providing well-planned professional knowledge and skill instruction as well as sufficient problemsolving assistance in the classroom; however, they paid less attention toward guiding students to establish effective team operations. The students taking the course did not have many opportunities to experience the learning process of team-based learning (TBL) and PBL. Therefore, the benefit of mutual growth among members with various skills within and across the group was not obtained. Second, the course TAs lacked sufficient knowledge and skills on how to play an active role in improving the effectiveness of team learning. Thus, some classroom interactions between the TAs and students were similar to senior students providing personal consultation instead of timely viewing the group's PBL work dynamics.

\section{Conclusions}

The NTUEE at NTU initiated two practical-oriented courses in the 2017-2018 academic year, namely the "Creative Cornerstone Course Design for ICT Engineering Education" junior-and-above-level course and the "Cornerstone EECS Design and Implementation" freshman-level course. The implementation characteristics of the co-designing course included (a) PBL and TBL approaches to develop and strengthen students' core abilities, such as problem solving, team communication, and cooperation, independently, (b) active student partnership with teachers to design and create feasible lesson plans for the freshman cornerstone course in following semester, and (c) preparatory cultivation of the students as TAs for co-teaching in the cornerstone course. Learning outcome analysis indicated that the freshman students significantly benefited in their self-exploration of ICT-related subjects, basic professional knowledge, operational techniques, and self-confidence in helping teams complete tasks when the freshman course was co-designed. With the professional assistance 
by an education expert from the Center for Teaching and Learning Development, the teaching team has been continuously enhancing the curriculum development model and PBL instructional skills for the cornerstone course.

\section{Acknowledgments}

This work was supported in part by the Department of Electrical Engineering, National Taiwan University, and by the Ministry of Education, Taiwan, ROC, under grants PED1080263 and PEE1080336.

\section{References}

Bovill, C. \& Bulley, C.J. (2011). A model of active student participation in curriculum design: Exploring desirability and possibility. In Rust, C. (ed.) Improving Student Learning 18: Global Theories and Local Practices: Institutional, Disciplinary and Cultural Variations. Oxford Brookes University: Oxford Centre for Staff and Learning Development.

Curran, R. \& Millard, L. (2016). A partnership approach to developing student capacity to engage and staff capacity to be engaging: opportunities for academic developers. International Journal for Academic Development, v21 n1 p67-78. doi: 10.1080/ 1360144042000277919

Delpish, A., Holmes, A., Knight-McKenna, M., Mihans, R., Darby, A., King, K. and Felten, P. (2010). equalizing voices: student-faculty partnership in course design. In: Werder, C. and Otis, M.M. (eds.), Engaging Student Voices in the Study of Teaching and Learning. Sterling, VA: Stylus, 96-114.

Dym, C. L., (2013). Engineering Design: A Project-Based Introduction, 4ed, Wiley, ISBN 1118324587.

Johri, A., and Olds, B. M. eds., (2014). Cambridge Handbook of Engineering Education Research, Cambridge. ISBN-13: 9781107014107.

Kuh, G. D., Kinzie, J., Schuh, J. H., and Whitt, E. J. and Associates American Association for Higher Education (2005), Student success in college: Creating conditions that matter. Jossey-Bass.

Mihans, R. J., Long, D., and Felten, P. (2008). Power and expertise: student-faculty collaboration in course design and the scholarship of teaching and learning, International Journal for the Scholarship of Teaching and Learning, 2(2), Article 16. doi:. 10.20429/ijsotl.2008.020216

Thompson, M. (2012). Fostering innovation in cornerstone design courses. International Journal of Engineering Education, Vol. 28, No. 2, pp. 325-338.

Vallim, M. B. R., Farines, J.-M., and Cury, J.E.R. (2006). Practicing engineering in a freshman introductory course" IEEE Transactions on Education, Volume: 49 Issue: 1.

Whitfield, C. A., Freuler, R. J., Allam, Y. and Riter, E. A. (2011). An overview of highly successful first-year engineering cornerstone design projects. Stanford University, http://www.ineer.org/Events/ICEE2011/papers/icee2011_submission_294.pdf 